\title{
Effects of UV-accelerated weathering and natural weathering conditions on anti-fungal efficacy of wood/PVC composites doped with propylene glycol-based HPQM
}

\author{
P. Srimalanon ${ }^{1}$, W. Yamsaengsung ${ }^{2}$, A. Kositchaiyong ${ }^{1}$, E. Wimolmala ${ }^{1}$, K. Isarangkura ${ }^{3}$, \\ N. Sombatsompop ${ }^{1 *}$ \\ ${ }^{1}$ Polymer PROcessing and Flow (P-PROF) Research Group, Division of Materials Technology, School of Energy, \\ Environment and Materials, King Mongkut's University of Technology Thonburi (KMUTT), 126 Pracha-utid Rd., \\ Bangmod, Thungkru, 10140 Bangkok, Thailand \\ ${ }^{2}$ School of Science and Technology, Sukhothai Thammathirat Open University, 9/9 Moo 9, Bangpood, Pakkret, 11120 \\ Nonthaburi, Thailand \\ ${ }^{3}$ Koventure Co., Ltd., 563 Moo 4, Bangpoo Industrial Estate Soi 10, Sukhumvit Rd., Praeksa, Muang, 10280 Samut \\ Prakan, Thailand
}

\begin{abstract}
This work studied the mechanical, physical and weathering properties and anti-fungal efficacy of polyvinyl chloride(PVC) and wood flour/polyvinyl chloride composites(WPVC). 2-hydroxypropyl-3-piperazinyl-quinoline carboxylic acid methacrylate (HPQM) in propylene glycol was used as an anti-fungal agent. Propylene glycol-based HPQM was doped in neat PVC and in WPVC containing 50 and 100 pph wood (WPVC-50 and WPVC-100). The flexural properties of PVC decreased when propylene glycol-based HPQM was added. However, adding this component did not affect the flexural properties of WPVC. Fungal growth inhibition test and dry weight technique were used for evaluation of anti-fungal effectiveness. Aspergillus niger was used as a testing fungus. Adding propylene glycol-based HPQM to WPVC-100 led to the most effective anti-fungal performance. Wood flour acted as an anti-fungal promoter for the WPVC composites. The optimal dosages of propylene glycol-based HPQM in PVC, WPVC-50, and WPVC-100 were 50000, 15000, and 10000 ppm, respectively. UV-accelerated weathering aging and natural weathering conditions were found to affect the flexural properties of PVC and WPVC. The change in the anti-microbial performance of WPVC under natural weathering were slower than those under UV-accelerated weathering aging. The anti-microbial evaluation indicated that the samples doped with less than 20000 ppm propylene glycol-based HPQM had a more pronounced effect than the ones doped with higher dosages.
\end{abstract}

Keywords: polymer composites, wood flour, anti-fungal activities, mechanical properties, environmental degradation

\section{Introduction}

Wood/polyvinyl chloride composites (WPVC) can be converted into numerous products for specific applications, such as in the construction and automotive industries, and are widely used due to their desirable properties including cost-effectiveness and easy customization $[1,2]$. For outdoor applications, various additives, e.g. stabilizers, reinforcing fillers, and bio- cides, must be added to WPVC in order to prevent the degradation of the composites [3-11].

Pilarski and Matuana [1] observed a decrease in flexural properties of WPVC due to the accelerated aging effect of freeze-thaw cycles and found that the aging leads to more moisture uptake in the composites, resulting in some deterioration of interfacial adhesion between the wood flour and the PVC matrix.

\footnotetext{
${ }^{*}$ Corresponding author, e-mail: narongrit.som@kmutt.ac.th (C) BME-PT
} 
Naumann et al. [10] and Dawson-Andoh et al. [4] reported the occurrence of surface micro- and macro-cracks in wood composite materials due to the accelerated weathering aging effect. The results suggest that the accelerated weathering aging effect under UV radiation, water spray, and repeated freezethaw cycles causes enhancement of moisture sorption and microbial attacks. According to studies on biological attack on materials, colonization by a variety of fungal species (wood-decay fungi, staining fungi, yeasts, and yeast-like fungi) has been mostly found on the surfaces of materials [4, 12-16]. Gumargalieva et al. [3] reported that Aspergillus niger, a degradative fungal species, colonizes the surfaces of plasticized-PVC (p-PVC), causing losses of plasticizer. Kaczmarek and Bajer [17] reported that the biodegradation process was significantly more accelerated in p-WPVC as compared with p-PVC when exposed to soil burial conditions, i.e. in forest soil and in soil enriched with microorganisms.

Typically, commercial biocides can be divided into two types: inorganic and organic. Inorganic biocides, which are derived from a chemical reaction process, are generally considered to have high thermal stability; while organic biocides, usually made from plant parts or produced by biochemical processes of living organisms, are normally subject to biodegradation in outdoor environments. Coulthwaite et al [18] reported 2-n-octyl-4-isothiazolin-3-one (OIT) encapsulated on silica or zeolite and showed the best long term anti-fungal performance of pPVC materials. Kositchaiyong et al. [19] reported that addition of anti-fungal agent (Carbendazim or IPBC) in WPVC composites tended to increase the anti-fungal (Aspergillus niger) efficacy. 2-Hydroxypropyl3-piperazinyl-quinoline carboxylic acid methacrylate (HPQM), or BioCleanAct ${ }^{\mathrm{TM}}$ (product code BCA101A0; Micro Science Tech Co., Ltd., Hwaseong, South Korea), is a new commercial anti-microbial agent that is claimed to be an environmental friendly organic biocide with low toxicity, light elution, and excellent color stability under UV light and pyrolysis conditions. Evidence [20,21] shows that HPQM performs well against a broad range of the microbial spectrum. Kawahara et al. [22] reported that HPQM has an anti-microbial effect against both gram-negative (e.g., Escherichia coli, Pseudomonas aeruginosa, and Salmonella typhimurium) and grampositive (e.g., Staphylococcus aureus, Bacillus subtilis, and Streptococcus aureus) bacteria.
Thus, the objective of this work was to study the effects of UV-accelerated weathering aging and natural weathering conditions on the mechanical and physical properties and the anti-fungal efficacy of polyvinyl chloride (PVC) and wood/polyvinyl chloride (WPVC) composites containing propylene glycol-based HPQM (as an anti-microbial agent). Propylene glycol-based HPQM with content ranging from 0 to $50000 \mathrm{ppm}$ was doped in PVC and in WPVC with wood flour content of 50 and $100 \mathrm{pph}$ (WPVC50 and WPVC-100). Fungal growth inhibition test and dry weight technique, using Aspergillus niger as a testing fungus, were employed to evaluate anti-fungal performance.

\section{Experimental}

\subsection{Materials and chemicals}

Suspension PVC with a $K$ value of 58 (Siamvic 258RB; Vinythai Public Co., Ltd., Rayong, Thailand), necessary additives, and wood flour from hardwood (V.P. Wood Co., Ltd., Bangkok, Thailand) were used in this work. The PVC and necessary additives were manufactured following the formulations given in our previous study [7]. Wood flour with an average particle size of 100 to $300 \mu \mathrm{m}$ was chemically treated with $\mathrm{N}$-2(aminoethyl)-3-aminopropyl trimethoxysilane (KBM-603; Shin-Etsu Chemical Co., Ltd., Tokyo, Japan) as a coupling agent. Propylene glycolbased HPQM (HPQM), in the form of a light yellow liquid, was used as an anti-fungal agent (Koventure Co., Ltd., Samut Prakan, Thailand), with the chemical formulation of 2-hydroxypropyl-3-piperazinylquinoline carboxylic acid methacrylate thiazole,

Table 1. Ingredients in PVC and WPVC compounds

\begin{tabular}{|l|c|}
\hline \multicolumn{1}{|c|}{ Chemical name } & $\begin{array}{c}\text { Content } \\
\left.\text { [pph }{ }^{*}\right]\end{array}$ \\
\hline Suspension PVC (Siamvic 258RB) & 100.0 \\
\hline Emulsion PVC (Siamvic 167GZ) & 4.0 \\
\hline $\begin{array}{l}\text { Thermal stabilizer } \\
\text { (Pb-Ba-based organic, PF 608A) }\end{array}$ & 3.6 \\
\hline Thermal stabilizer (PF 601) & 1.5 \\
\hline External lubricant (Finalux-G 741) & 0.6 \\
\hline Internal lubricant (calcium stearate) & 0.6 \\
\hline Filler (calcium carbonate, Omyacarb ${ }^{\circledR}$ 2T) & 12.0 \\
\hline $\begin{array}{l}\text { Impact modifier } \\
\text { (modified chlorinated polyethylene) }\end{array}$ & 7.7 \\
\hline Processing aid (acrylic, PA-20) & 6.0 \\
\hline Wood flour & $0,50,100$ \\
\hline Silane coupling agent (KBM-603) & $1 \mathrm{wt} \%$ of wood \\
\hline $\begin{array}{l}\text { Anti-microbial agent } \\
\text { (propylene glycol-based HPQM) }\end{array}$ & $0-50000$ ppm ${ }^{* *}$ \\
\hline
\end{tabular}

*pph: parts per hundred; ${ }^{* *}$ ppm: parts per million 
freezing point of $-59^{\circ} \mathrm{C}$ and boiling point of $188^{\circ} \mathrm{C}$. Aspergillus niger was used as a testing fungus $(A$. niger, TISTR 3245; Thailand Institute of Scientific and Technological Research, Thailand). Necessary additives included thermal stabilizers, external and internal lubricants, calcium carbonate as a filler, modified chlorinated polyethylene as an impact modifier, and an acrylic polymer as a processing aid (Table 1).

\subsection{Sample preparation}

The wood flour was chemically surface-treated with $\mathrm{N}$-2(aminoethyl)-3-aminopropyl trimethoxysilane at $1.0 \mathrm{wt} \%$ of wood flour content using a high-speed mixer at $1000 \mathrm{rpm}$ for $5 \mathrm{~min}$. Treated wood flour was then dried in a hot-air oven at $80^{\circ} \mathrm{C}$ for $72 \mathrm{~h}$ [7]. The PVC compound was dry-blended with treated wood flour and HPQM using a high-speed mixer at $1000 \mathrm{rpm}$ for $5 \mathrm{~min}$. The components of PVC and WPVC, including the necessary additives, are listed in Table 1. HPQM at a content of 0, 1000, 5000, $10000,15000,20000$, and 50000 ppm of PVC compound was doped in PVC and in WPVC containing wood flour at 50 and 100 pph of PVC compound (WPVC-50 and WPVC-100). All compositions were melt-blended using a counter-rotating twin-screw extruder (HAAKE ${ }^{\mathrm{TM}}$ Rheomex CTW 100 QC; Thermo Scientific, Waltham, MA, USA) at temperatures of $140,150,160$ and $160^{\circ} \mathrm{C}$ for feed zone to die, respectively. A screw speed of $40 \mathrm{rpm}$ was used to produce pellets of PVC, WPVC-50, and WPVC100 with different HPQM contents; the pellets were then dried in a hot-air oven at $80^{\circ} \mathrm{C}$ for $24 \mathrm{~h}$ to remove moisture. Test specimen pellets were prepared using a compression molding machine (LP-20M; Labtech Engineering, Samut Songkhram, Thailand) at $170^{\circ} \mathrm{C}$ under a pressure of $150 \mathrm{~kg} / \mathrm{cm}^{2}$ for 8 min.

\subsection{Material characterizations}

\subsubsection{Flexural properties}

Flexural properties were measured following the standard test method ASTM D790 (2010), using a universal testing machine (Autograph AG-I; Shimadzu, Kyoto, Japan). The flexural properties of specimens were investigated in terms of flexural modulus and strength. The results were averaged from at least five independent determinations.

\subsubsection{Surface contact angle measurement}

Surface contact angle value was determined following ASTM D7334 (2008) using a contact angle goniometer (100-00; Ramé-hart Instrument Co., Succasunna, NJ, USA). Surface contact angle value referred to changes of surface chemistry, surface energy, and hydrophobicity of PVC and WPVC. The results were averaged from at least five independent droplets at $100 \mu \mathrm{L} /$ time of dropped volume size in advancing stage using distilled water as wetting liquid.

\subsubsection{Surface morphology}

The morphological properties of PVC and WPVC were photographed using a scanning electron microscope (JSM-6301F; JEOL, Tokyo, Japan) under $15 \mathrm{kV}$ of accelerating voltage and backscattering detection mode. The aim of the tests was to study the fracture surface of specimens before and after weathering testing. For specimen preparation, all samples were dried, cleaned, and then gold-coated using a sputter coater before being photographed.

\subsubsection{Surface color change}

Surface color change of the specimens was measured with a UV-Vis-NIR recording spectrophotometer (UV-3100; Shimadzu, Japan) in accordance with ASTM D1746 (2009), using the Hunter Lab system. The surface color change of specimens was investigated in terms of lightness level $\left(L^{*}\right)$. The results were averaged from at least five independent determinations.

\subsection{Evaluation of fungal growth}

\subsubsection{Fungal growth inhibition test}

Fungal growth inhibition [19] against $A$. niger, a testing fungus, was used for anti-fungal evaluation of specimens. The procedure was commenced by preparing an initial fungal spore suspension containing $10^{4}$ spores $/ \mathrm{mL}$ in $100 \mathrm{~mL}$ of $1: 1$ potato dextrose broth (PDB)/potato dextrose agar (PDA). One piece of specimen $\left(30 \times 30 \mathrm{~cm}^{2}\right)$ was placed on PDA in a Petri dish $(9 \mathrm{~cm}$ diameter). Prepared fungal spores were then poured onto the specimen in the dish and incubated at a temperature of $25^{\circ} \mathrm{C}$ for 7 days. The results were reported as percent of fungal growth inhibition, as shown in Equation (1):

Percent of fungal growth inhibition $=\frac{A_{\mathrm{C}}}{A_{\mathrm{S}}} \cdot 100$ 
where $A_{\mathrm{C}}$ and $A_{\mathrm{S}}$ are the area of fungal growth inhibition on the specimen surface $[\mathrm{mm}]$ and the area of the specimen surface [mm], respectively. Each area was calculated using the ImageJ program.

\subsubsection{Dry weight technique}

The technique was modified from the determination of fungal growth as described in previous studies $[23,24]$. The procedure was commenced by preparing an initial fungal spore suspension containing $10^{4}$ spores $/ \mathrm{mL}$ in $100 \mathrm{~mL}$ PDB. Two pieces of specimens $\left(2.5 \times 5 \mathrm{~cm}^{2}\right)$ were placed into the prepared fungal medium in an Erlenmeyer flask and then shaken at $150 \mathrm{rpm}$ at an incubation temperature of $25^{\circ} \mathrm{C}$ for 14 days. After the incubation period, the specimens were collected from the PDB medium and the growing fungi removed by vacuum filtration using high wet-strength Whatman No. 1 filter paper. The filtered fungi were oven-dried at $80^{\circ} \mathrm{C}$ for $48 \mathrm{~h}$ and then cooled in a desiccator until reaching a constant weight. The weight of growing fungi was calculated by subtracting the weight of the filter paper from the total weight, and was reported in terms of dry weight of fungi in $\mathrm{mg} / \mathrm{L}$, as governed by Equation (2):

Dry weight of fungi $=\frac{W_{\mathrm{d}}}{V_{\mathrm{m}}}$

where $W_{\mathrm{d}}$ is the dry weight of filtered fungi $[\mathrm{mg}]$ and $V_{\mathrm{m}}$ is the volume of the PDB medium used $(100 \mathrm{~mL})$.

\subsection{Accelerated weathering studies}

\subsubsection{UV-accelerated weathering aging testing}

Testing was performed following ASTM G154 (2012) cycle I using a QUV Accelerated Weathering Tester (Q-LAB, Westlake, OH, USA). The conditions of UV-weathering aging testing included exposure to UVA radiation at a wavelength of $340 \mathrm{~nm}$ and intensity of $0.77 \mathrm{~W} / \mathrm{m}^{2}$ at $60^{\circ} \mathrm{C}$ for $8 \mathrm{~h}$, and water condensation at $50^{\circ} \mathrm{C}$ for $4 \mathrm{~h}$. The aging times were varied at $0,4,8,16$, and 32 days.

\subsubsection{Natural weathering testing}

Testing was performed in accordance with ASTM D1435 (2005). The specimens were exposed on racks at a $45^{\circ}$ angle in a southerly direction on a roof deck at the School of Energy, Environment and Materials building at King Mongkut's University of Technology Thonburi, Bangkok, Thailand, for 52 days during March and April 2014. The conditions for natural weathering testing included UVA radiation at a wavelength of $340 \mathrm{~nm}$ and intensity of $0.67 \mathrm{~W} / \mathrm{m}^{2}$ tested by spectroradiometer series CAS140CT-154 (approved by the National Institute of Metrology of Thailand), temperature 26.7 to $36.9^{\circ} \mathrm{C}$, rainfall $23.7 \mathrm{~mL} /$ day, and relative humidity $72.5 \%$. Climate data were provided by National Institute of Metrology of Thailand and The Thai Meteorological Department. The natural weathering times were varied at $0,14,28,42$, and 56 days.

\section{Results and discussion}

\subsection{Effects of HPQM and wood flour contents}

The results of the fungal growth inhibition test and the dry weight technique against $A$. niger for PVC, WPVC-50, and WPVC-100 with different HPQM contents are shown in Figure 1. In general, a greater percentage of fungal growth inhibition usually indicates better anti-microbial efficacy of a material. Figure 1a shows the anti-microbial efficacy in terms of percent of fungal growth inhibition against $A$. niger of PVC at 0,50 , and $100 \mathrm{pph}$ of wood flour doped with HPQM. The minimum HPQM contents to attain $100 \%$ fungal growth inhibition for PVC, WPVC-50, and WPVC-100 were 50000, 15000, and $10000 \mathrm{ppm}$, respectively. It was found that the anti-fungal efficacy of PVC increased with increasing HPQM and wood flour contents. This suggests that the wood flour allows more HPQM to migrate onto the WPVC composite surfaces. An explanation for this phenomenon is that introducing the wood flour, which is highly hydrophilic in nature $[25,26]$ into the WPVC makes the PVC become more hydrophilic. As a consequence, more water molecules can be absorbed into/onto the HPQM/WPVC surfaces [19]. Another possible reason was that the methoxy groups $\left(-\mathrm{OCH}_{3}\right)$ in the aminosilane could be hydrolyzed to produce silanol $\left[-\mathrm{OSi}(\mathrm{OH})_{3}\right]$ and these silanol groups would develop covalent siloxane bonds by reaction with $\mathrm{OH}$ groups of wood during the wood flour pretreatment process, and then the PVC could bond with the amine group of aminosilane modified wood flour by an acid-base interaction [27-29]. Accordingly, wood flour acts as an anti-fungal promoter for the WPVC due to its preliminary treatment with amino-based silane coupling agent which reduces the degree of water absorption [30].

Figure $1 \mathrm{~b}$ shows the anti-fungal efficacy in terms of dry weight against $A$. niger of $\mathrm{PVC}$ at 0,50 , and $100 \mathrm{pph}$ of wood flour doped with HPQM. In general, the lower the dry weight of the fungus, the better 
the anti-fungal efficacy of the material. In this case, the dry weight of $A$. niger (Figure 1b) decreased with increasing wood flour and HPQM contents. This suggests that wood flour acts as an anti-fungal promoter for WPVC [31]. This property was clearly seen for wood flour contents of 50 and $100 \mathrm{pph}$. The findings also correspond well to the percent of fungal growth inhibition results shown in Figure 1a.

Table 2 shows the surface contact angle values of PVC and WPVC with different HPQM and wood flour contents. It was observed that adding HPQM tended to lower the surface contact angle values of
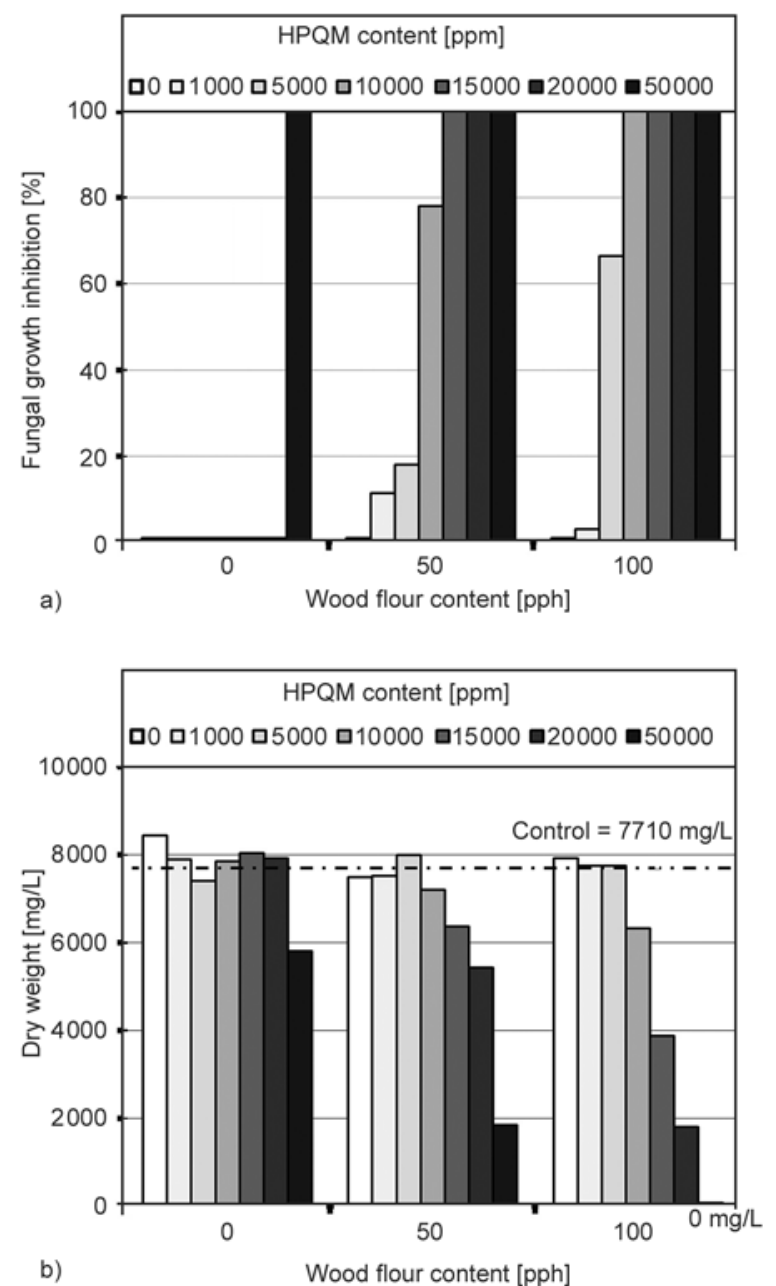

Figure 1. Anti-fungal efficacy of PVC, WPVC-50, and WPVC-100 with different HPQM content: (a) fungal growth inhibition values, and (b) dry weight values
PVC and WPVC materials. This implies greater hydrophilicity of the PVC and WPVC when HPQM was introduced into the composites due to the high polarity and hydrophilicity of HPQM, which probably migrated onto the PVC and WPVC surfaces. It was also found that the higher the wood flour content, the lower the surface contact angle values. This would be associated with the hydrophilicity of the wood flour in WPVC composites, with high water absorption and polarity. The changes in the hydrophilicity of WPVC by adding wood flour are related to the increase in the number of hydroxyl groups in the wood fiber structure.

\subsection{Effects of QUV-accelerated weathering aging and natural weathering conditions}

Anti-fungal efficacy and surface morphology of the PVC and WPVC specimens from the effects of QUVaccelerated weathering are shown in Figures 2 and 3 with respect to the degree of fungal growth inhibition (quantitative analysis) and the results of scanning electron micrographs (SEM) (qualitative analysis), respectively. Figure 2a shows the anti-fungal efficacy in terms of fungal growth inhibition for neat PVC with varying HPQM content under the effect of QUV-accelerated weathering. The degree of fungal growth inhibition for the PVC samples decreased significantly with increasing QUV aging time. The water condensation process accompanying the degradation of the neat PVC during QUV aging could be the main reason for this drastic reduction in the antifungal activity of PVC samples. When the PVC samples encountered UV light, some cracks would occur due to PVC degradation. The HPQM was thus able to migrate more easily, or be released through the cracks, and was eventually washed away in the water condensation process during QUV aging. The number of cracks for neat PVC increased with increasing aging time (Figure $3 \mathrm{a}-3 \mathrm{c}$ ). These results correspond well with Sributr et al. [32]. The findings indicate that HPQM in neat PVC was not capable of maintaining anti-fungal efficacy under prolonged UV light exposure.

Table 2. Contact angles of PVC, WPVC-50, and WPVC-100 with different HPQM content. Mean $( \pm$ SD).

\begin{tabular}{|c|c|c|c|c|c|c|c|}
\hline $\begin{array}{c}\text { Wood flour } \\
\text { content } \\
\text { [pph] }\end{array}$ & \multicolumn{7}{|c|}{$\begin{array}{c}\text { HPQM content } \\
\text { [ppm] }\end{array}$} \\
\cline { 2 - 8 } & $\mathbf{0}$ & $\mathbf{1 0 0 0}$ & $\mathbf{5 0 0 0}$ & $\mathbf{1 0 0 0 0}$ & $\mathbf{1 5 0 0 0}$ & $\mathbf{2 0 0 0 0}$ & $\mathbf{5 0 0 0 0}$ \\
\hline 0 & $90.9^{\circ}( \pm 0.7)$ & $88.3^{\circ}( \pm 0.3)$ & $88.5^{\circ}( \pm 0.9)$ & $86.8^{\circ}( \pm 0.5)$ & $84.9^{\circ}( \pm 1.0)$ & $80.8^{\circ}( \pm 1.2)$ & $72.9^{\circ}( \pm 2.2)$ \\
\hline 50 & $81.6^{\circ}( \pm 2.1)$ & $80.6^{\circ}( \pm 1.6)$ & $80.1^{\circ}( \pm 1.8)$ & $79.2^{\circ}( \pm 1.5)$ & $77.9^{\circ}( \pm 1.0)$ & $75.3^{\circ}( \pm 0.5)$ & $70.5^{\circ}( \pm 1.8)$ \\
\hline 100 & $78.2^{\circ}( \pm 1.0)$ & $77.8^{\circ}( \pm 1.1)$ & $77.3^{\circ}( \pm 2.0)$ & $74.1^{\circ}( \pm 0.2)$ & $73.6^{\circ}( \pm 0.3)$ & $73.4^{\circ}( \pm 0.2)$ & $66.7^{\circ}( \pm 0.1)$ \\
\hline
\end{tabular}


Figure $2 b$ shows the anti-fungal efficacy in terms of fungal growth inhibition for WPVC-50 with varying HPQM content under the effect of QUV-accelerated weathering. From day 0 to day 8 , it was observed that the degree of fungal growth inhibition for the WPVC50 sample with HPQM content of 5000 ppm increased with increasing QUV aging time. Then, from day 8 to day 32 the degree of fungal growth inhibition for

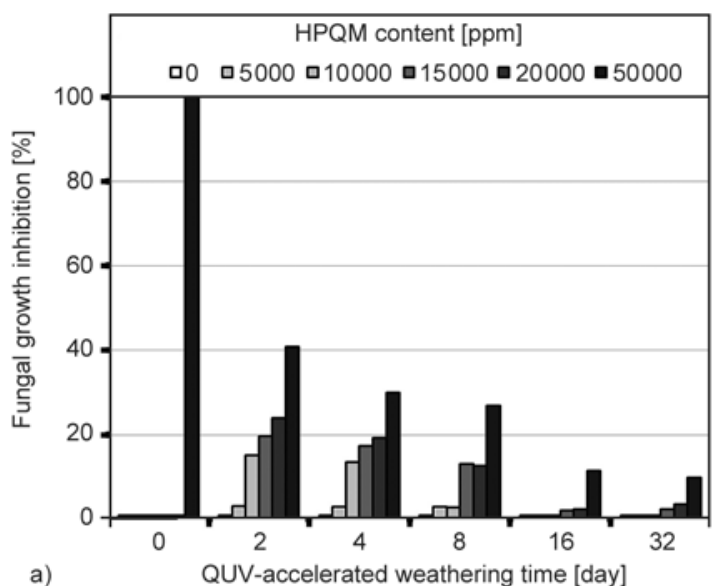

a)

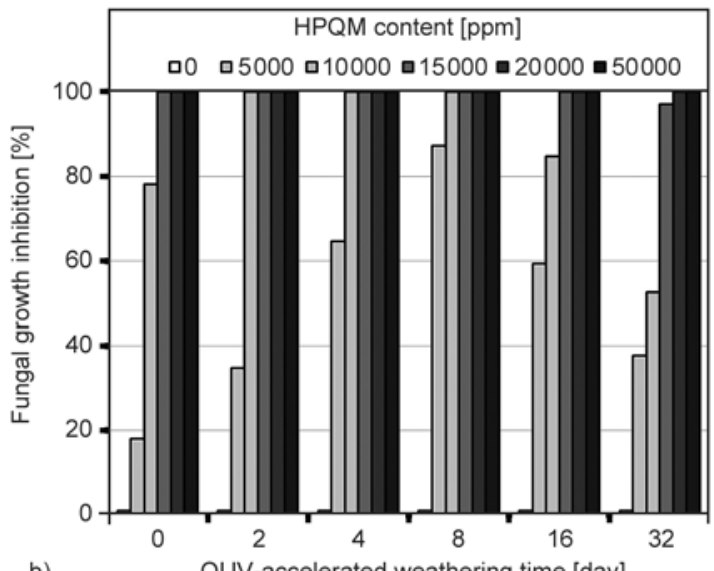

b)

QUV-accelerated weathering time [day]

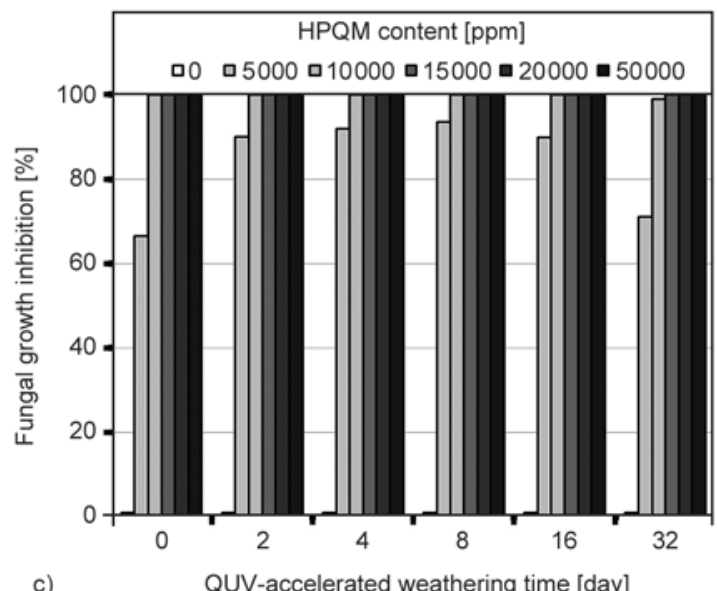

Figure 2. Fungal growth inhibition values for (a) PVC, (b) WPVC-50, and (c) WPVC-100 with different HPQM content, after QUV-accelerated weathering aging the WPVC-50 sample decreased with increasing QUV aging time. During the first few days of aging, the low anti-fungal efficacy of WPVC-50 was caused by HPQM being trapped by the PVC matrix, thus limiting the diffusion rate of HPQM in the composites. The limited diffusion rate of HPQM may be caused by both H-bonding between HPQM and the coupling agent and dipole-dipole interaction between HPQM and carbon atoms in the PVC matrix. The decrease in the degree of fungal growth inhibition for the WPVC-50 sample after day 8 involved the water condensation process accompanying the degradation of the WPVC-50 during QUV aging, which initiated some cracks on the WPVC-50 composite, thereby increasing the diffusion rate of HPQM through the cracks. The number of cracks for WPVC50 increased with increasing aging time, as shown in Figure 3d-3f. These results correspond well with Sributr et al. [32]. During the condensation process, some of the HPQM was washed away from the composite samples, resulting in a decrease in anti-fungal growth inhibition, as shown in Figure 2b. Similar results, but with more pronounced anti-fungal efficacy, were shown for WPVC-100 with varying HPQM content under the effect of QUV-accelerated weathering (Figure 2c); the surface morphological properties illustrating the results are shown in Figure $3 \mathrm{~g}-3 \mathrm{i}$.

Figures 4 and 5 show the effects of natural weathering conditions on the anti-fungal efficacy and surface morphology (from SEM) of neat PVC and of WPVC-50 and WPVC-100 composites with varying HPQM content. Figure $4 \mathrm{a}$ shows the effects of natural weathering conditions on the anti-fungal efficacy of neat PVC with varying HPQM content. Before natural weathering, the anti-fungal efficacy of neat PVC with 50000 ppm HPQM reached $100 \%$ of fungal growth inhibition. Under natural weathering, the anti-fungal efficacy of PVC was generally found to decrease with increasing weathering time. This can be explained by the water condensation process accompanying the degradation of the neat $\mathrm{PVC}$, as mentioned previously. However, at day 56 neat PVC regained some of its anti-fungal efficacy, from 20 to around $48 \%$. In this case, when the PVC samples were exposed to UV light, some cracks would occur due to PVC degradation (Figure 5c). The HPQM was then able to migrate more easily (or be released through the cracks), thus increasing the anti-fungal efficacy of neat PVC. 

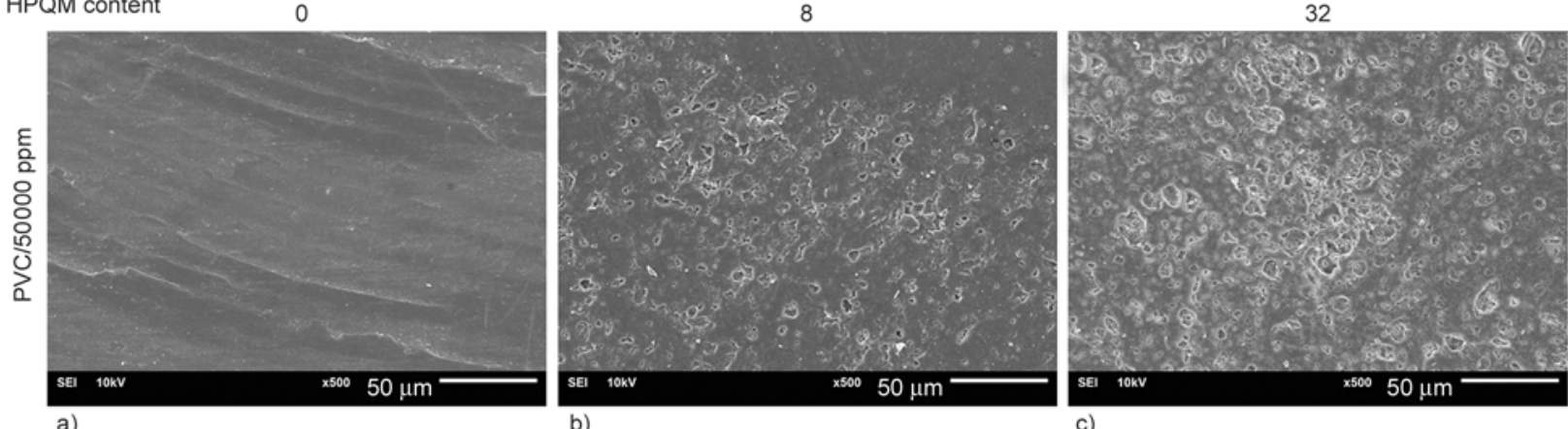

a)

\section{b)}

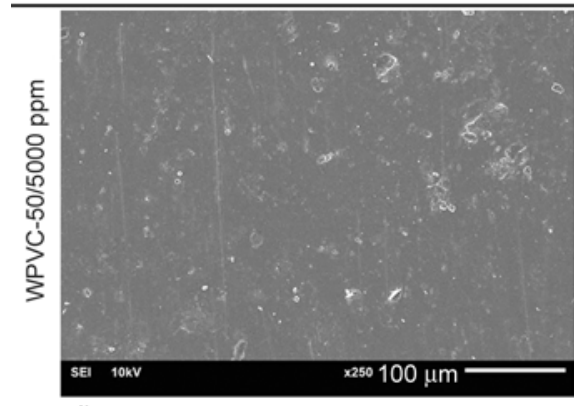

d)
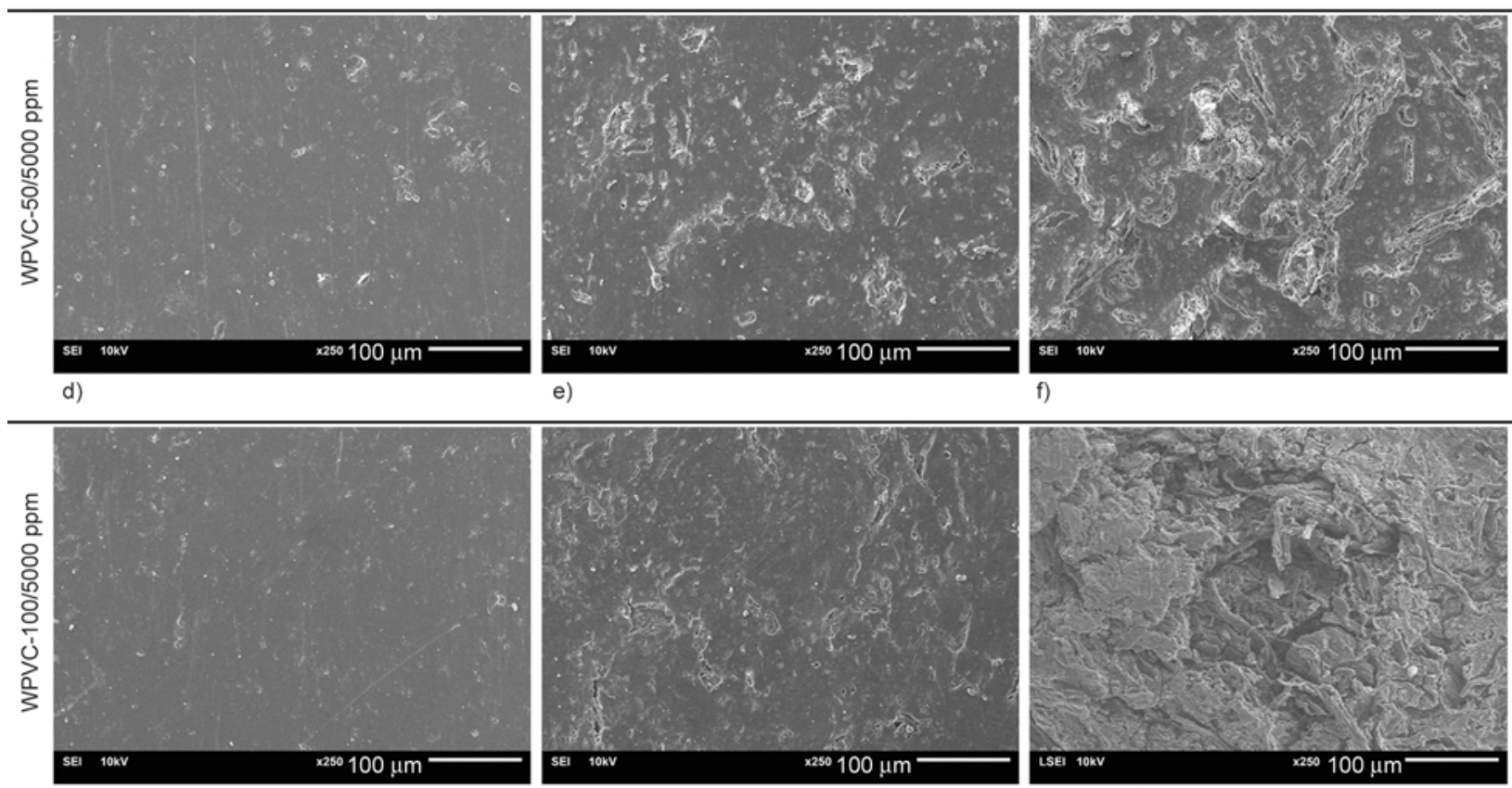

g)

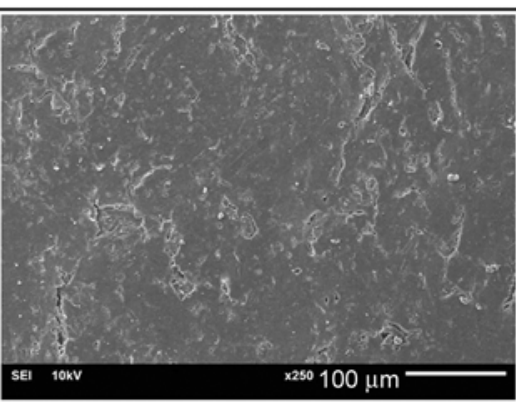

f)

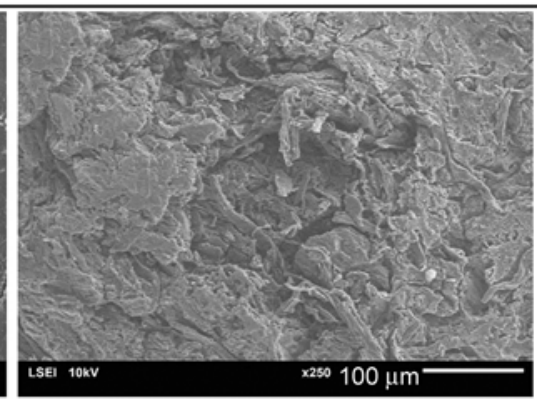

h)

i)

Figure 3. Scanning electron micrographs showing the surface morphology of PVC (a-c), WPVC-50 (d-e), and WPVC$100(\mathrm{~g}-\mathrm{i})$ doped with HPQM, after QUV-accelerated weathering aging

Figure $4 \mathrm{~b}$ shows the effects of natural weathering conditions on the anti-fungal efficacy of WPVC-50 with varying HPQM content. Before natural weathering, the minimum concentration of HPQM which resulted in $100 \%$ of fungal growth inhibition was $15000 \mathrm{ppm}$. Under natural weathering, the anti-fungal efficacy of WPVC-50 was found to decrease with increasing weathering time for any given HPQM content (other than $50000 \mathrm{ppm}$ ) until day 56, when the anti-fungal efficacy of WPVC-50 increased. As in the case of neat PVC, when the WPVC-50 samples encountered UV light, some cracks would occur due to WPVC-50 degradation (Figure 5d-5f), allowing the HPQM to migrate more easily (or be released through the cracks) and thus increase the anti-fungal efficacy of WPVC-50.

Figure $4 \mathrm{c}$ shows the effects of natural weathering conditions on the anti-fungal efficacy of WPVC-
100 with varying HPQM content. Before natural weathering, the minimum concentration of $\mathrm{HPQH}$ necessary to achieve $100 \%$ of fungal growth inhibition was $10000 \mathrm{ppm}$. Under natural weathering, the anti-fungal efficacy of WPVC-100 was found to decrease with increasing weathering time and then increase at day 56. Figure $5 \mathrm{~g}-5 \mathrm{i}$ shows the surface morphology during natural weathering of WPVC100 doped with 10000 ppm HPQM. When comparing between QUV weathering (Figure 2) and natural weathering (Figure 4), the reduction of anti-fungal efficacy for neat PVC and WPVC was more pronounced for QUV weathering. It is known that radiation from sunlight under natural weathering conditions includes visible light, UV, and infrared radiation; whereas the radiation from a UVB lamp under QUV weathering conditions contains only UV radiation $(280-380 \mathrm{~nm})$ [33]. In general, radiation at UV 
wavelengths is primarily responsible for PVC degradation. In this case, UV radiation under natural weathering was much lower than under QUV weathering. This is the reason for greater PVC and WPVC degradation under QUV weathering as compared with natural weathering.
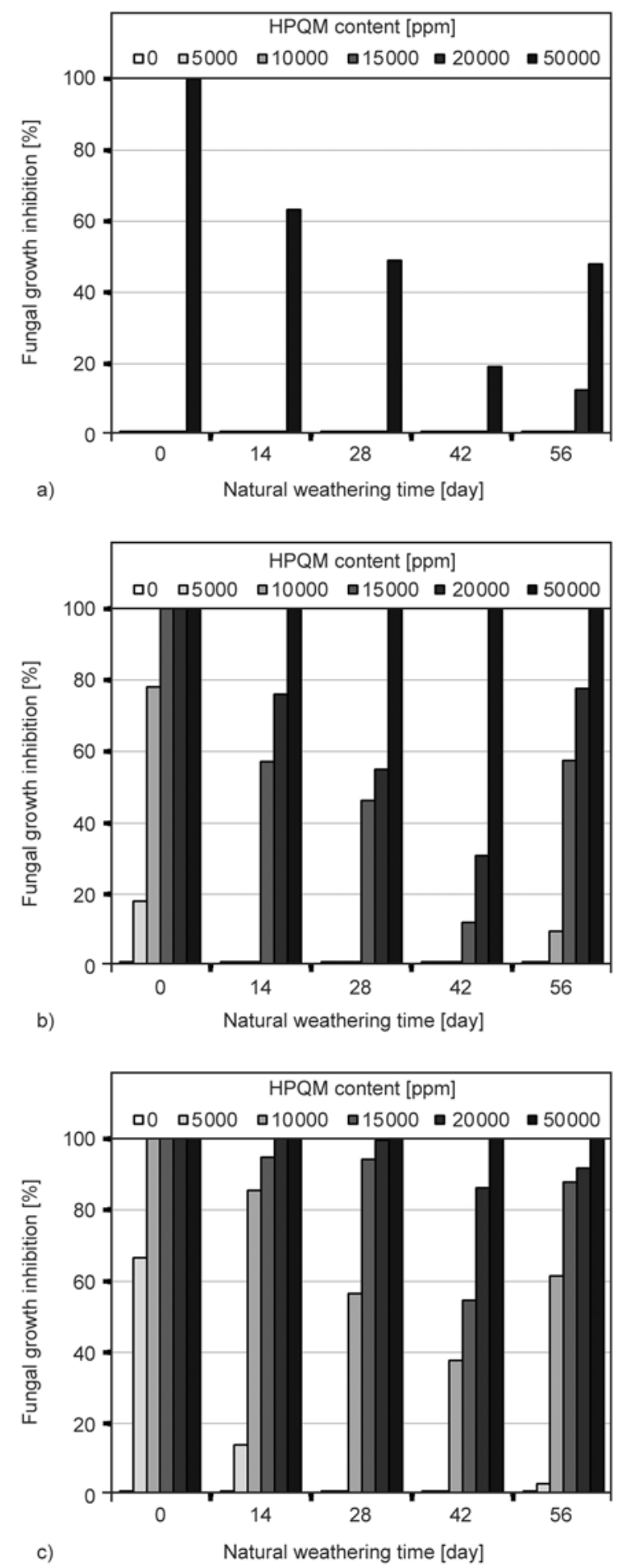

Figure 4. Fungal growth inhibition values for (a) PVC, (b) WPVC-50, and (c) WPVC-100 with different HPQM content, after natural weathering
Figure 6 shows the release behavior model of HPQM in the WPVC matrix when exposed to QUV-accelerated weathering aging and natural weathering. The release behavior of HPQM is composed of four stages: I) initial stage, II) water discharge, III) surface cracks, and IV) more surface cracks with respect to time or severity of QUV-accelerated weathering aging. Figure 6a shows stage I of the WPVC matrix, before applying weathering aging. This stage shows three types of HPQM activity on the WPVC composites: 1) forming H-bonds with the silane coupling agent, 2) forming dipole-dipole interaction with carbon atoms in the WPVC matrix, and 3) releasing HPQM species on the WPVC surface. Figure 6b shows stage II, the water-discharge stage, of the release behavior of HPQM in the WPVC matrix. In this stage, the degree of fungal growth inhibition for the WPVC decreased with increasing weathering time. This is because only the free HPQM on the top surface could achieve anti-fungal efficacy. Most of the HPQM was trapped by the PVC matrix. Figure 6c shows stage III, surface cracks, of the release behavior of HPQM in the WPVC matrix. In this stage, the degree of fungal growth inhibition for the WPVC increased with increasing weathering time. This is because the water condensation process accompanying the degradation of the WPVC generated some cracks; this allowed HPQM to migrate more easily, or be released through the cracks, and eventually be washed away in the water condensation process during QUV aging. In general, HPQM is replaced by water molecules, forming $\mathrm{H}$-bonds with the $\mathrm{OH}-$ groups of the wood flour. Figure $6 \mathrm{~d}$ shows stage IV, more surface cracks from the release behavior of HPQM in the WPVC matrix. In this stage, the degree of fungal growth inhibition for the WPVC decreased with increasing weathering time. This is because less HPQM is left in the WPVC.

Figure 7 shows the timeline of the release behavior of HPQM in the WPVC matrix when exposed to QUV-accelerated weathering aging and natural weathering. Natural weathering occurs in three stages: (I) initialization, (II) water-discharge, and (III) surface cracks. However, for QUV-accelerated weathering aging, there are four stages: (I) initialization, (II) water-discharge, (III) surface cracks, and (IV) more surface cracks. Both natural weathering and QUV-accelerated weathering aging had similar effects on the anti-microbial performance changes for 


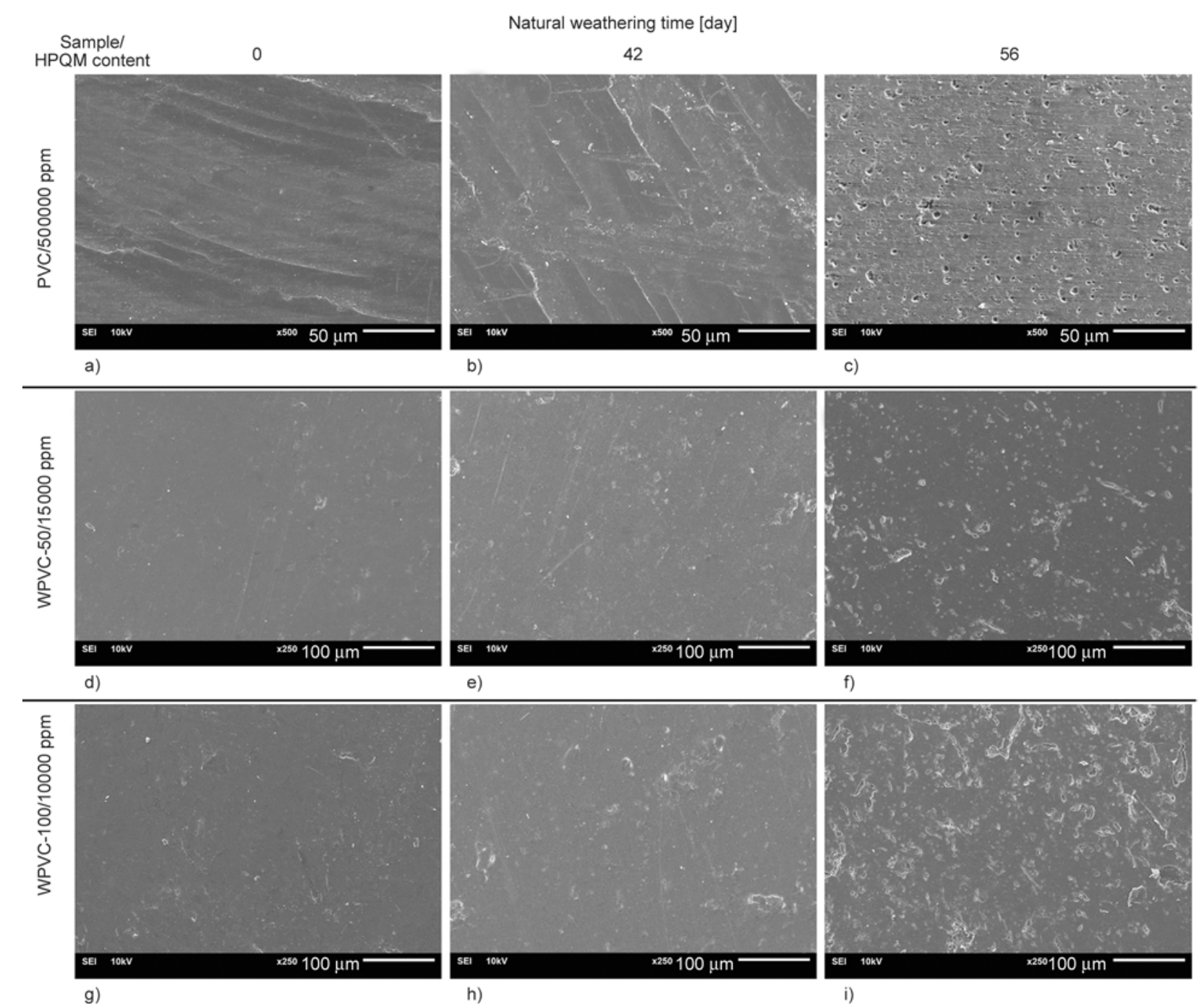

Figure 5. Scanning electron micrographs showing the surface morphology of PVC (a-c), WPVC-50 (d-f), and WPVC100 (g-i) doped with HPQM, after natural weathering

Table 3. Flexural and physical properties of PVC and WPVC before and after QUV-accelerated weathering aging. Mean ( \pm SD).

\begin{tabular}{|c|c|c|c|c|c|c|c|}
\hline \multirow{3}{*}{ Sample } & \multirow{3}{*}{$\begin{array}{c}\text { HPQM } \\
\text { content } \\
\text { [ppm] }\end{array}$} & \multicolumn{6}{|c|}{ QUV-accelerated weathering aging } \\
\hline & & \multicolumn{2}{|c|}{$\begin{array}{c}\text { Flexural modulus } \\
{[\mathrm{MPa}]}\end{array}$} & \multicolumn{2}{|c|}{$\begin{array}{c}\text { Flexural strength } \\
{[\mathrm{MPa}]}\end{array}$} & \multicolumn{2}{|c|}{$\begin{array}{c}\text { Lightness } \\
\left(L^{*}\right)\end{array}$} \\
\hline & & Before & After & Before & After & Before & After \\
\hline \multirow{6}{*}{$\mathrm{PVC}$} & 0 & $2347.52( \pm 128.06)$ & $2477.54( \pm 78.40)$ & $60.84( \pm 1.33)$ & $70.64( \pm 1.22)$ & $80.32( \pm 0.46)$ & $54.23( \pm 3.55)$ \\
\hline & 5000 & $2332.90 \quad( \pm 89.58)$ & $2327.12( \pm 156.40)$ & $60.04( \pm 0.61)$ & $70.85( \pm 2.46)$ & $80.25( \pm 0.11)$ & $54.86( \pm 0.56)$ \\
\hline & 10000 & $2096.87 \quad( \pm 88.31)$ & $2358.64( \pm 33.53)$ & $55.45( \pm 2.51)$ & $64.71( \pm 3.42)$ & $79.71( \pm 0.41)$ & $53.27( \pm 3.22)$ \\
\hline & 15000 & $2147.14 \quad( \pm 72.09)$ & $2229.32( \pm 107.60)$ & $53.02( \pm 1.12)$ & $65.78( \pm 1.35)$ & $80.26( \pm 0.27)$ & $50.49( \pm 0.99)$ \\
\hline & 20000 & $2033.49 \quad( \pm 71.46)$ & $2247.46( \pm 97.20)$ & $52.30( \pm 0.88)$ & $64.42( \pm 1.65)$ & $79.28( \pm 0.31)$ & $44.89( \pm 1.46)$ \\
\hline & 50000 & $2015.70 \quad( \pm 14.35)$ & $2019.31( \pm 153.02)$ & $45.62( \pm 1.03)$ & $56.06( \pm 1.46)$ & $75.89( \pm 0.42)$ & $42.07( \pm 0.52)$ \\
\hline \multirow{6}{*}{ WPVC-50 } & 0 & $2903.49( \pm 124.63)$ & $1936.92( \pm 71.72)$ & $38.35( \pm 1.62)$ & $33.05( \pm 1.82)$ & $28.92( \pm 0.31)$ & $79.84( \pm 0.23)$ \\
\hline & 5000 & $3019.40( \pm 147.11)$ & $2028.31( \pm 101.44)$ & $40.48( \pm 1.40)$ & $31.53( \pm 1.19)$ & $28.99( \pm 0.30)$ & $77.59( \pm 0.73)$ \\
\hline & 10000 & $3089.78 \quad( \pm 98.48)$ & $2036.32( \pm 53.53)$ & $40.61( \pm 1.82)$ & $32.13( \pm 0.88)$ & $29.20( \pm 0.08)$ & $78.62( \pm 0.51)$ \\
\hline & 15000 & $3009.10( \pm 160.80)$ & $1980.18( \pm 94.87)$ & $40.65( \pm 3.38)$ & $28.55( \pm 1.38)$ & $28.61( \pm 0.29)$ & $75.46( \pm 0.59)$ \\
\hline & 20000 & $2972.06( \pm 122.81)$ & $2263.35( \pm 102.86)$ & $39.90( \pm 1.47)$ & $33.02( \pm 2.33)$ & $29.17( \pm 0.16)$ & $76.47( \pm 0.37)$ \\
\hline & 50000 & $3024.31( \pm 116.08)$ & $2132.36( \pm 91.84)$ & $40.02( \pm 2.12)$ & $31.99( \pm 1.77)$ & $28.41( \pm 0.06)$ & $76.28( \pm 0.29)$ \\
\hline \multirow{6}{*}{ WPVC-100 } & 0 & $3434.00( \pm 111.41)$ & $1617.47( \pm 157.51)$ & $37.54( \pm 1.23)$ & $21.33( \pm 0.95)$ & $28.43( \pm 0.17)$ & $74.41( \pm 0.28)$ \\
\hline & 5000 & $3502.67( \pm 284.04)$ & $1877.49( \pm 56.98)$ & $40.78( \pm 2.27)$ & $26.23( \pm 1.80)$ & $28.62( \pm 0.33)$ & $72.97( \pm 0.24)$ \\
\hline & 10000 & $3691.17 \quad( \pm 50.71)$ & $2056.45( \pm 122.58)$ & $37.46( \pm 0.05)$ & $24.63( \pm 2.83)$ & $28.10( \pm 0.01)$ & $72.51( \pm 0.59)$ \\
\hline & 15000 & $3471.54( \pm 155.10)$ & $2188.33( \pm 198.51)$ & $37.80( \pm 2.30)$ & $26.61( \pm 2.93)$ & $28.28( \pm 0.10)$ & $73.45( \pm 0.91)$ \\
\hline & 20000 & $3464.02( \pm 122.43)$ & $1934.47( \pm 160.18)$ & $40.59( \pm 2.13)$ & $26.94( \pm 0.91)$ & $26.97( \pm 0.23)$ & $72.03( \pm 0.92)$ \\
\hline & 50000 & $3421.22( \pm 136.13)$ & $1800.69( \pm 190.37)$ & $39.11( \pm 0.39)$ & $25.45( \pm 2.63)$ & $27.30( \pm 0.14)$ & $69.23( \pm 0.42)$ \\
\hline
\end{tabular}



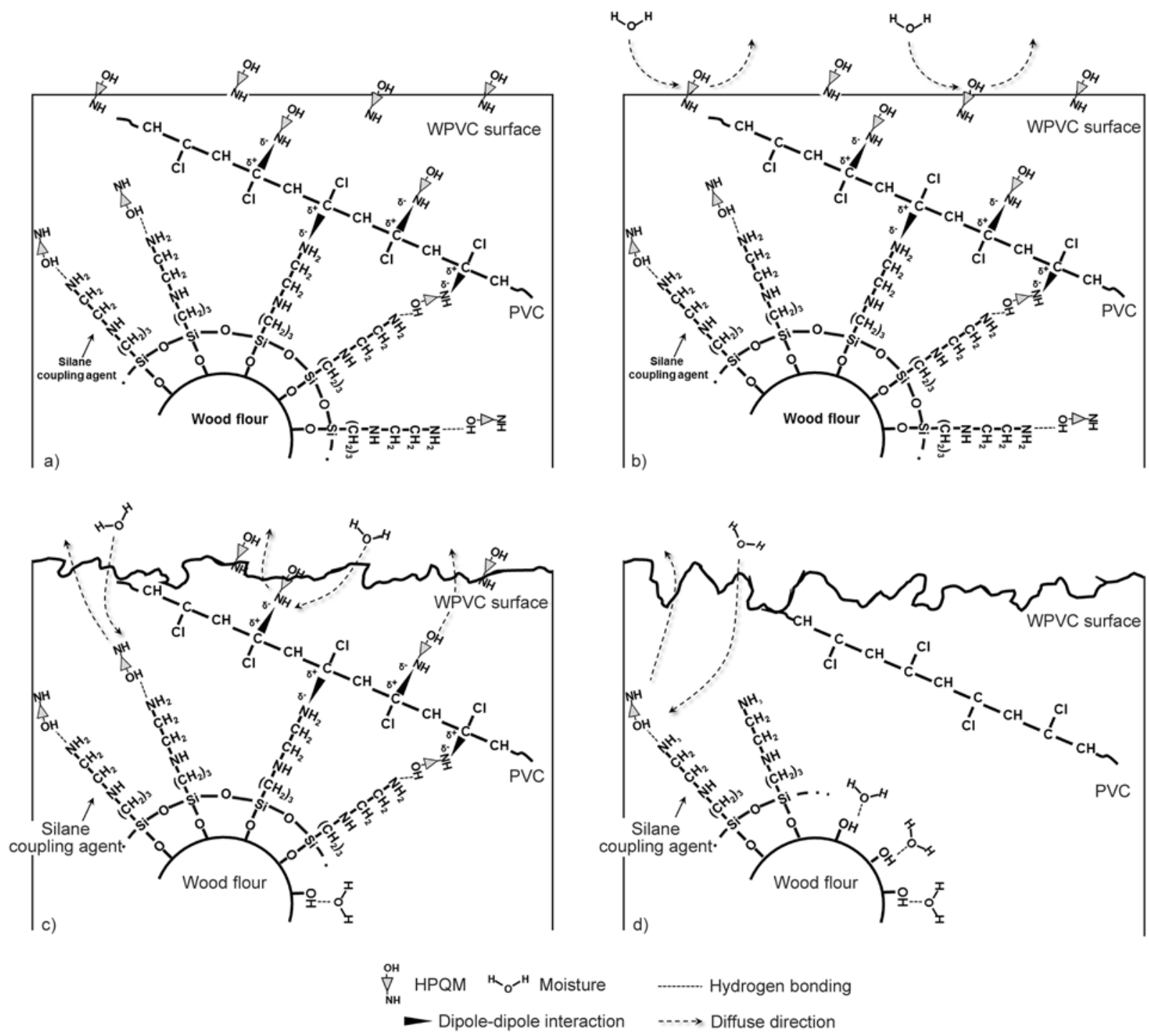

Figure 6. Release behavior of HPQM in the WPVC matrix when exposed to QUV-accelerated weathering aging or natural weathering: (a) initial stage, (b) water discharge, (c) surface cracks, and (d) more surface cracks with respect to time or severity of QUV-accelerated weathering aging

PVC and WPVC composites, but the changes were slower for natural weathering. This can also be explained by the differences in energy provided by natural weathering and QUV aging, as discussed earlier and in Chaochanchaikul et al. [33].

Tables 3 and 4 show the flexural and physical properties of PVC and WPVC before and after QUVaccelerated weathering aging and natural weathering. The results show that the flexural modulus for neat PVC was not affected by QUV-accelerated weathering aging and natural weathering. This is because of the high polarity and strong molecular interaction of PVC molecules. When considering the effect of wood flour, the flexural modulus of the WPVC-50 and WPVC-100 composites decreased with increased QUV-accelerated weathering aging

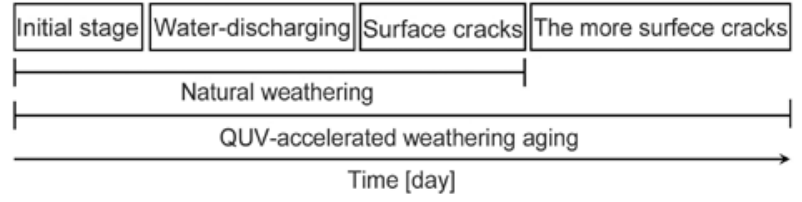

Figure 7. Timeline of release behavior of HPQM in the WPVC matrix when exposed to QUV-accelerated weathering aging and natural weathering

and natural weathering time. This can be explained by the moisture absorption ability of the wood flour. During the aging process, wood flour absorbed moisture, decreasing the interfacial adhesion between wood fibers and the polymer matrix. Moreover, the presence of wood appeared to accelerate the photodegradation of WPVC under QUV-accelerated weathering aging conditions and to decrease the 
Table 4. Flexural and physical properties of PVC and WPVC before and after natural weathering. Mean $( \pm \mathrm{SD})$.

\begin{tabular}{|c|c|c|c|c|c|c|c|}
\hline \multirow{3}{*}{ Sample } & \multirow{3}{*}{$\begin{array}{c}\text { HPQM } \\
\text { content } \\
\text { [ppm] }\end{array}$} & \multicolumn{6}{|c|}{ Natural weathering } \\
\hline & & \multicolumn{2}{|c|}{$\begin{array}{c}\text { Flexural modulus } \\
\text { [MPa] }\end{array}$} & \multicolumn{2}{|c|}{$\begin{array}{c}\text { Flexural strength } \\
{[\mathrm{MPa}]}\end{array}$} & \multicolumn{2}{|c|}{$\begin{array}{l}\text { Lightness } \\
\left(L^{*}\right)\end{array}$} \\
\hline & & Before & After & Before & After & Before & After \\
\hline \multirow{6}{*}{ PVC } & 0 & $2347.52( \pm 128.06)$ & $2386.68( \pm 261.33)$ & $60.84( \pm 1.33)$ & $64.81( \pm 1.08)$ & $80.32( \pm 0.46)$ & $74.15( \pm 0.16)$ \\
\hline & 5000 & $2332.90 \quad( \pm 89.58)$ & $2364.36( \pm 234.67)$ & $60.04( \pm 0.61)$ & $65.37( \pm 0.70)$ & $80.25( \pm 0.11)$ & $70.21( \pm 0.25)$ \\
\hline & 10000 & $2096.87 \quad( \pm 88.31)$ & $2225.36( \pm 107.51)$ & $55.45( \pm 2.51)$ & $64.72( \pm 0.05)$ & $79.71( \pm 0.41)$ & $69.30( \pm 0.14)$ \\
\hline & 15000 & $2147.14 \quad( \pm 72.09)$ & $2236.44( \pm 138.36)$ & $53.02( \pm 1.12)$ & $60.17( \pm 2.51)$ & $80.26( \pm 0.27)$ & $68.34( \pm 0.03)$ \\
\hline & 20000 & $2033.49 \quad( \pm 71.46)$ & $2172.27 \quad( \pm 99.78)$ & $52.30( \pm 0.88)$ & $56.87( \pm 2.25)$ & $79.28( \pm 0.31)$ & $67.25( \pm 0.06)$ \\
\hline & 50000 & $2015.70 \quad( \pm 14.35)$ & $2008.24( \pm 139.28)$ & $45.62( \pm 1.03)$ & $50.58( \pm 2.43)$ & $75.89( \pm 0.42)$ & $53.00( \pm 0.45)$ \\
\hline \multirow{6}{*}{ WPVC-50 } & 0 & $2903.49( \pm 124.63)$ & $2345.43( \pm 125.86)$ & $38.35( \pm 1.62)$ & $35.74( \pm 1.31)$ & $28.92( \pm 0.31)$ & $70.56( \pm 0.75)$ \\
\hline & 5000 & $3019.40( \pm 147.11)$ & $2423.23( \pm 72.72)$ & $40.48( \pm 1.40)$ & $35.72( \pm 1.00)$ & $28.99( \pm 0.30)$ & $73.88( \pm 0.90)$ \\
\hline & 10000 & $3089.78( \pm 98.48) 1$ & $2365.63 \quad( \pm 79.67)$ & $40.61( \pm 1.82)$ & $35.04( \pm 0.47)$ & $29.20( \pm 0.08)$ & $74.78( \pm 1.03)$ \\
\hline & 15000 & $3009.10( \pm 160.80)$ & $2404.08 \quad( \pm 67.88)$ & $40.65( \pm 3.38)$ & $35.86( \pm 4.27)$ & $28.61( \pm 0.29)$ & $74.19( \pm 1.19)$ \\
\hline & 20000 & $2972.06( \pm 122.81)$ & $2360.26( \pm 235.72)$ & $39.90( \pm 1.47)$ & $37.35( \pm 0.42)$ & $29.17( \pm 0.16)$ & $72.83( \pm 0.60)$ \\
\hline & 50000 & $3024.31( \pm 116.08)$ & $2347.39( \pm 139.47)$ & $40.02( \pm 2.12)$ & $37.23( \pm 2.04)$ & $28.41( \pm 0.06)$ & $71.47( \pm 0.64)$ \\
\hline \multirow{6}{*}{ WPVC-100 } & 0 & $3434.00( \pm 111.41)$ & $2400.56 \quad( \pm 68.82)$ & $37.54( \pm 1.23)$ & $29.03( \pm 0.07)$ & $28.43( \pm 0.17)$ & $74.98( \pm 0.33)$ \\
\hline & 5000 & $3502.67( \pm 284.04)$ & $2528.45( \pm 128.96)$ & $40.78( \pm 2.27)$ & $30.04( \pm 0.53)$ & $28.62( \pm 0.33)$ & $73.89( \pm 0.16)$ \\
\hline & 10000 & $3691.17 \quad( \pm 50.71)$ & $2300.54( \pm 189.01)$ & $37.46( \pm 0.05)$ & $30.39( \pm 2.25)$ & $28.10( \pm 0.01)$ & $74.85( \pm 0.28)$ \\
\hline & 15000 & $3471.54( \pm 155.10)$ & $2346.40( \pm 42.29)-$ & $37.80( \pm 2.30)$ & $29.54( \pm 0.52)$ & $28.28( \pm 0.10)$ & $74.32( \pm 0.64)$ \\
\hline & 20000 & $3464.02( \pm 122.43)$ & $2220.97( \pm 272.09)$ & $40.59( \pm 2.13)$ & $28.09( \pm 2.29)$ & $26.97( \pm 0.23)$ & $73.78( \pm 0.17)$ \\
\hline & 50000 & $3421.22( \pm 136.13)$ & $2149.28( \pm 98.26)-$ & $39.11( \pm 0.39)$ & $29.35( \pm 1.32)$ & $27.30( \pm 0.14)$ & $73.98( \pm 0.35)$ \\
\hline
\end{tabular}

mechanical properties of the WPVC. This can be explained by the induced dipole-dipole interaction between $\mathrm{OH}-$ groups of wood flour and $\mathrm{Cl}$ atoms on the PVC chain [33].

The flexural strength of neat PVC increased during QUV-accelerated weathering aging and natural weathering. The increased flexural strength after aging can be explained by the presence of polyene [33]. In the case of WPVC-50 and WPVC-100, the flexural strength decreased during QUV-accelerated weathering aging and natural weathering. The decrease in flexural strength after aging can be explained by the same reason given above. When comparing between QUV-accelerated weathering aging and natural weathering, the reduction of flexural strength for WPVC-50 and WPVC-100 was more pronounced for QUV weathering. This is because the UV radiation under natural weathering was much lower than under QUV-accelerated weathering aging, which explains the greater WPVC degradation under QUV-accelerated weathering aging as compared with natural weathering.

The results of discoloration testing (Tables 3 and 4) for QUV-accelerated weathering aging and natural weathering indicate that the lightness $\left(L^{*}\right)$ of neat PVC decreased with aging. This can be explained by the degradation of PVC, which is confirmed by the presence of polyene. However, the lightness of
WPVC-50 and WPVC-100 increased with aging. The increase in lightness of the WPVC composites after QUV-accelerated weathering aging and natural weathering can be explained by the lignin structure in wood flour changing from hydroquinone to para-quinone [34].

\section{Conclusions}

Adding wood flour to the PVC matrix could improve the anti-fungal efficacy of the WPVC composites. For killing fungi, the optimal dosages of propylene glycol-based HPQM in PVC, WPVC-50, and WPVC100 were 50000,15000 , and 10000 ppm, respectively. When comparing QUV-accelerated weathering aging and natural weathering, it was observed that the reduction of flexural strength for WPVC-50 and WPVC-100 was more pronounced for QUV weathering. The flexural properties of WPVC were found to decrease with increasing QUV-accelerated weathering aging and natural weathering, but this was not the case for neat PVC samples. The anti-fungal evaluation indicated that the samples doped with less than 20000 ppm propylene glycol-based HPQM had a more pronounced effect than the ones doped with higher dosages. The release behavior of HPQM in the WPVC matrix was dependent on the type of aging, PVC degradation, and water condensation during the aging process. The change in the anti-fungal per- 
formance of WPVC under natural weathering was the same as that under QUV-accelerated weathering aging, but the rate of change was slower.

\section{Acknowledgements}

The authors would like to thank the Thailand Research Fund (TRF) for a Senior Research Scholar Grant (RTA 5580009) and a Researchers and Research for Industry Grant (MSD 5610082). Appreciation is also expressed to the Office of the Higher Education Commission (Thailand) under the National Research Universities program, and to Koventure Co., Ltd. (Thailand), for financial support. The authors are grateful to the College of Industrial Technology, King Mongkut's University of Technology North Bangkok (KMUTNB), for the use of laboratory facilities.

\section{References}

[1] Pilarski J. M., Matuana L. M.: Durability of wood flour-plastic composites exposed to accelerated freezethaw cycling. Part I. Rigid PVC matrix. Journal of Vinyl and Additive Technology, 11, 1-8 (2005). DOI: $10.1002 /$ vnl.20029

[2] Pattamasattayasonthi N., Chaochanchaikul K., Rosarpitak V., Sombatsompop N.: Effects of UV weathering and $\mathrm{CeO}_{2}$-based coating layer on the mechanical and structural changes of wood/PVC composites. Journal of Vinyl and Additive Technology, 17, 9-16 (2011). DOI: $10.1002 / \mathrm{vnl} .20246$

[3] Gumargalieva K. Z., Zaikov G. E., Semenov S. A., Zhdanova O. A.: The influence of biodegradation on the loss of a plasticiser from poly(vinyl chloride). Polymer Degradation and Stability, 63, 111-112 (1999). DOI: 10.1016/S0141-3910(98)00071-8

[4] Dawson-Andoh B., Matuana L. M., Harrison J.: Mold susceptibility of rigid PVC/wood-flour composites. Journal of Vinyl and Additive Technology, 10, 179-186 (2004).

DOI: $10.1002 / \mathrm{vnl} .20027$

[5] Sombatsompop N., Phromchirasuk C.: Effects of acrylic based processing aids on processability, rheology, thermal and structural stability, and mechanical properties of PVC/wood sawdust composites. Journal of Applied Polymer Science, 92, 782-790 (2004).

DOI: 10.1002/app.13641

[6] El-Aghoury A., Vasudeva R. K., Banu D., Elektorowicz M., Feldman D.: Contribution to the study of fungal attack on some plasticized vinyl formulations. Journal of Polymers and the Environment, 14, 135-147 (2006). DOI: 10.1007/s10924-006-0004-9

[7] Chaochanchaikul K., Sombatsompop N.: Stabilizations of molecular structures and mechanical properties of PVC and wood/PVC composites by Tinuvin and $\mathrm{TiO}_{2}$ stabilizers. Polymer Engineering and Science, 51, 1354-1365 (2011). DOI: $10.1002 /$ pen. 21893
[8] Faruk O., Bledzki A. K., Fink H-P., Sain M.: Biocomposites reinforced with natural fibers: 2000-2010. Progress in Polymer Science, 37, 1552-1596 (2012). DOI: 10.1016/j.progpolymsci.2012.04.003

[9] Jeamtrakull S., Kositchaiyong A., Markpin T., Rosarpitak V., Sombatsompop N.: Effects of wood constituents and content, and glass fiber reinforcement on wear behavior of wood/PVC composites. Composites Part B: Engineering, 43, 2721-2729 (2012).

DOI: 10.1016/j.compositesb.2012.04.031

[10] Naumann A., Stephan I., Noll M.: Material resistance of weathered wood-plastic composites against fungal decay. International Biodeterioration and Biodegradation, 75, 28-35 (2012).

DOI: $10.1016 /$ j.ibiod.2012.08.004

[11] Fang Y., Wang Q., Guo C., Song Y., Cooper P. A.: Effect of zinc borate and wood flour on thermal degradation and fire retardancy of polyvinyl chloride (PVC) composites. Journal of Analytical and Applied Pyrolysis, 100, 230-236 (2013).

DOI: $10.1016 /$ j.jaap.2012.12.028

[12] Kırbaş Z., Keskin N., Güner A.: Biodegradation of polyvinylchloride (PVC) by white rot fungi. Toxicology Bulletin of Environmental Contamination, 63, 335-342 (1999).

DOI: $10.1007 / \mathrm{s} 001289900985$

[13] Gu J-D.: Microbiological deterioration and degradation of synthetic polymeric materials: Recent research advances. International Biodeterioration and Biodegradation, 52, 69-91 (2003). DOI: $10.1016 / \mathrm{S} 0964-8305(02) 00177-4$

[14] Lugauskas A., Levinskaite L., Peciulyte D.: Micromycetes as deterioration agents of polymeric materials. International Biodeterioration and Biodegradation, 52, 233-242 (2003).

DOI: $10.1016 / \mathrm{S} 0964-8305(03) 00110-0$

[15] Lucas N., Bienaime C., Belloy C., Queneudec M., Silvestre F., Nava-Saucedo J. E.: Polymer biodegradation: Mechanisms and estimation techniques - A review. Chemosphere, 73, 429-442 (2008).

DOI: 10.1016/j.chemosphere.2008.06.064

[16] Lomelí-Ramírez M. G., Ochoa-Ruiz H. G., FuentesTalavera F. J., García-Enriquez S., Cerpa-Gallegos M. A., Silva-Guzmán J. A.: Evaluation of accelerated decay of wood plastic composites by Xylophagus fungi. International Biodeterioration and Biodegradation, 63, 10301035 (2009).

DOI: 10.1016/j.ibiod.2009.08.002

[17] Kaczmarek H., Bajer K.: Biodegradation of plasticized poly(vinyl chloride) containing cellulose. Journal of Polymer Science Part B: Polymer Physics, 45, 903919 (2007).

DOI: $10.1002 /$ polb. 21100 
[18] Coulthwaite L., Bayley K., Liauw C., Craig G., Verran J.: The effect of free and encapsulated OIT on the biodeterioration of plasticised PVC during burial in soil for 20 months. International Biodeterioration and Biodegradation, 56, 86-93 (2005).

DOI: $10.1016 /$ j.ibiod.2005.06.001

[19] Kositchaiyong A., Rosarpitak V., Sombatsompop N.: Antifungal properties and material characteristics of PVC and wood/PVC composites doped with carbamate-based fungicides. Polymer Engineering and Science, 54, 1248-1259 (2014).

DOI: $10.1002 /$ pen.23672

[20] Abuo-Rahma G. E. A. A., Sarhan H. A., Gad G. F. M.: Design, synthesis, antibacterial activity and physicochemical parameters of novel $N$-4-piperazinyl derivatives of norfloxacin. Bioorganic and Medicinal Chemistry, 17, 3879-3886 (2009).

DOI: $10.1016 /$ j.bmc.2009.04.027

[21] Zhang Z., Zhou W., Yu A.: Synthesis and antibacterial activity of 7-(Substituted)aminomethyl quinolones. Bioorganic and Medicinal Chemistry Letters, 14, 393-395 (2004).

DOI: $10.1016 /$ j.bmcl.2003.10.059

[22] Kawahara K., Tsuruda K., Morishita M., Uchida M.: Antibacterial effect of silver-zeolite on oral bacteria under anaerobic conditions. Dental Materials, 16, 452455 (2000). DOI: 10.1016/S0109-5641(00)00050-6

[23] Ikeda Y., Park E. Y., Okuda N.: Bioconversion of waste office paper to gluconic acid in a turbine blade reactor by the filamentous fungus Aspergillus niger. Bioresource Technology, 97, 1030-1035 (2006).

DOI: 10.1016/j.biortech.2005.04.040

[24] Gitchaiwat A., Kositchaiyong A., Sombatsompop K., Prapagdee B., Isarangkura K., Sombatsompop N.: Assessment and characterization of antifungal and antialgal performances for biocide-enhanced linear lowdensity polyethylene. Journal of Applied Polymer Science, 128, 371-379 (2013).

DOI: $10.1002 / a p p .37675$

[25] Danilov R. A., Ekelund N. G. A.: Comparison of usefulness of three types of artificial substrata (glass, wood and plastic) when studying settlement patterns of periphyton in lakes of different trophic status. Journal of Microbiological Methods, 45, 167-170 (2001). DOI: $10.1016 / \mathrm{S} 0167-7012(01) 00247-0$
[26] Lewin M., Goldstein I. S.: Wood structure and composition. Marcel Dekker, New York (1991).

[27] Matuana M. L., Woodhams T. R., Balatinecz J. J., Park B. C.: Influence of interfacial interactions on the properties of PVC/cellulosic fiber composites. Polymer Composites, 19, 446-455 (1998).

DOI: $10.1002 / p c .10119$

[28] George J., Sreekala S. M., Thomas S.: A review on interface modification and characterization of natural fiber reinforced plastic composites. Polymer Engineering and Science, 41, 1471-1485 (2001). DOI: 10.1002/pen.10846

[29] Yue P., Chen G., Zhou S.: Improved interfacial bonding of PVC/wood-flour composites by lignin amine modification. Bioresources, 6, 2022-2034 (2011).

DOI: 10.15376/biores.6.2.2022-2044

[30] Yim H., Kim S. D.: Physical properties of PVC/aminosilane-treated wood flour/organoclay composites. Polymers for Advanced Technologies, 23, 1441-1445 (2012). DOI: $10.1002 /$ pat.2065

[31] Prapruddivongs C., Sombatsompop N.: Roles and evidence of wood flour as an antibacterial promoter for triclosan-filled poly(lactic acid). Composites Part B: Engineering, 43, 2730-2737 (2012).

DOI: 10.1016/j.compositesb.2012.04.032

[32] Sributr A., Yamsaengsung W., Wimolmala E., Kositchaiyong A., Israngkura K., Sombatsompop N.: Effects of solution and solid forms of 2-hydroxypropyl-3piperazinyl-quinoline carboxylic acid methacrylate on antibacterial, physical and mechanical properties of polypropylene sheeting. Journal of Plastic Film and Sheeting, 31, 248-268 (2014). DOI: $10.1177 / 8756087914561137$

[33] Chaochanchaikul K., Rosarpitak V., Sombatsompop N.: Photodegradation profiles of PVC compound and wood/PVC composites under UV weathering. Express Polymer Letters, 7, 146-160 (2013).

DOI: 10.3144 /expresspolymlett.2013.14

[34] Muasher M., Sain M.: The efficacy of photostabilizers on the color change of wood filled plastic composites. Polymer Degradation and Stability, 91, 1156-1165 (2006).

DOI: 10.1016/j.polymdegradstab.2005.06.024 